\title{
Stellarium as An Interactive Multimedia to Enhance Students' Understanding and Motivation in Learning Solar System
}

\author{
Risma Marina ${ }^{1}$, Eka Cahya Prima ${ }^{2}$ \\ \{risma.marina@student.upi.edu ${ }^{1}$, ekacahyaprima@upi.edu ${ }^{2}$ \} \\ Department of Science Education, Faculty of Mathematics and Science Education, Universitas \\ Pendidikan Indonesia, Bandung, Indonesia ${ }^{1,2}$
}

\begin{abstract}
This research aims to determine the effectiveness of Stellarium as an Interactive Multimedia to students' understanding and motivation in learning the solar system. This study used a quasi-experimental design. The research was conduct in one of the private schools in Bandung which the number of students is 41 . The Objective Test Item and Questionnaire were used as the research instrument. These instruments were given to experimental and control class as pretest and posttest. According to the analyses result, the value of Normalized gain in the experimental class and control class is 0.33 and 0.2. According to the Independent sample test result, the hypothesis in this research was accepted. The value of sig (2-tailed) is 0.019 with a significance value is 0.05 . Thus, there is different of students' understanding using Stellarium in learning solar system; The students' motivation in learning solar system using Stellarium is categorized as adequately motivated.
\end{abstract}

Keywords: Interactive Multimedia, Solar System, Stellarium, Students' Motivation, Students' understands

\section{Introduction}

Curriculum 2013 expects that students in Indonesia by the student profile of the 21st century, there are: innovator, problem solver, risk-taker, open-minded, communicator, team works, reflective, knowledgeable, and opportunity creator. Related with the implementation of Curriculum 2013, the government has emphasized the use of scientific approaches in the learning process. Application of the scientific method to learning involving process skills such as observing, classifying, measuring, predicting, explained, and concluded [1].

In fact, in the real condition, the purpose of curriculum 2013 is hard to be achieved, especially in a science subject. Students always consider that science subject is difficult and complicated. Also, science subject is regarded as an abstract concept and daunting for students [2]. The most challenging issue in science is physics because they have to comprehend the science content with different representations, such as experiments, formulas and calculations, graphs and conceptual explanations at the same time [3]. Besides, they must understand the abstract concept that we cannot be observed directly, with our eyes, and also abstract concept is too hard to imagine and to explain. Thus, they have to think hard.

Based on the result of the interview some students in a different school stated that the most difficult in science is physics. They consider that physic is a difficult subject especially 
to solve the problem and mastery concept or physics laws. Furthermore, they have less motivation to learn physic concepts. Many factors influence students learning. The condition affects students 'understanding and motivation in learning especially physics.

Students' motivation is essential to affect students 'achievement. Motivation refers to the reasons that underlie behavior characterized by willingness and volition [4]. Student motivation is probably the most critical element of learning. Although learning is hard, however, when the students have a high motivation they will enjoy the learning process. Learning is inherently hard work. It is pushing the brain to its limits so that it can only happen with high motivation. Highly motivated students will learn readily and make any class fun to teach, while unmotivated students will learn very little and generally make teaching painful and frustrating [5]. According to the interview, some students agreed that motivation is essential. Because it can make the aim of learning is achieved. They were stating if there is no motivation then they have no spirit. Consequently, they will feel lazy to learn. They prefer to fall asleep and not pay attention to the teacher.

There are many ways to improve students' motivation, one of the ways of conducting lessons using multimedia. Stellarium is one of the interactive multimedia. Because we lived in the $21^{\text {st }}$ century, also technology is developed well. Moreover, the development of globalization also affects the teaching-learning process. The development of media is commonly applied to the teaching-learning process. Media is one of the most important to support the teaching-learning process. The media-suffused environment today, the improvement of technologies has aroused the more and effective approaches production in a teaching-learning context. The derive of educational innovations have steered more innovative development for the interactive technology in varied forms, such as computer-based instruction (CBI), intelligent tutoring systems (ITS), integrated learning system (ILS), computer-aided assessment and computer-mediated communication [6].

The process of learning is very complicated. The work can be enforced on students by giving a lot of effort. They need a lot of motivation to enjoy the learning process. According to Steyowati, on his study stated that in terms of student learning will be successful, if in itself there is a willingness to learn and desire or encouragement to learn. Because of the increased motivation to learn, students will focus on learning, and not doing activities that are not related to the learning process. In this research, an educational software Stellarium will stimulate the student's interest to increase their motivation. As known in some area technology is growing fast, it can be observed how they use technology, especially with a computer game. Many adolescents and children are interested in computer games to enjoying their life [7]. Learning the solar system is quite abstract to be describing directly. Opinions are stating the wrong concept of the solar system. The cassis one is about flat earth theory. This cassis is interested many people are confused about whether the earth is flat or not. Students were questioning the same thing. In this case, Stellarium is proposed to help the students understanding by showing the real situation of the solar system to make the fact abstract clearer.

One of the physics concepts that have an abstract explanation is the motion of the planet in our solar system. In the solar system, to be described clearly. First, the planet cannot be identified directly by naked eyes. Second, the idea of earth rotation and earth revolution are quite abstract to be defined. Therefore, the simulation may help the students understanding of learning solar system. The previous investigation showed that the expository description of the planetary motion in learning solar system sometimes make students being bored. Based on this argumentation, the research will investigate the effectiveness of Stellarium as a learning media to improve students' understanding and motivation in learning solar system. 


\section{Research Method}

The research method that is used in this research was quasi-experiment. According to the best, Creswell [8] stated that Quasi-experiments include assignment, but not the random assignment of participants to groups. Researchers who employ these designs rely instead on other techniques to control (or at least reduce) threats to internal validity. The quasiexperimental approach introduces considerably more threats to internal validity than the true experiment. Because the investigator does not randomly assign participants to groups, the potential risks of maturation, selection, mortality, and the interaction of choice with other threats are possibilities.

The design used in this research was pre-test and post-test design as seen in Table 1 . The researcher assigns whole groups the experimental and control treatments, administers a pretest to both groups, conducts preliminary treatment activities with the experimental group only, and then administers a post-test to assess the differences between the two groups.

Table 1. Pre-test and post-test design

\begin{tabular}{llll}
\hline Group & Test & Treatment & Test \\
\hline Select Control Group & Pre-test & Learning without Stellarium & Post-test \\
Select Experimental Group & Pre-test & Learning with Stellarium & Post-test \\
\hline
\end{tabular}

The research was conducted at one of Junior Independent High school precisely in Padalarang, West Bandung which conducted at a period of 2016/2017. The curriculum that is used in this school is 2013 of Curriculum or it called Kurtilas (National Curriculum). They used bilingual as the instructional language.

The population in this research was $8^{\text {th }}$-grade students at International Junior High School in Bandung which use 2013 of Curriculum who have not studied the solar system topic. Three classes provide for this research. Thus the researcher conducted sampling selection to determine which is an experimental group and control group. The sampling technique that is used for this research was convenience sampling. A convenience sample is a group of individuals who (conveniently) are available for study. The researcher selects participants because they are willing and available to be studied. The researcher decides to study this group at this one school because they are available and because the researcher has the permission of the principal.

The consideration is because the researcher chooses sample based on the requirement such as the school implemented the curriculum 2013, and students who will learn about a concept that will be tested due to limited and resources The samples are two classes in $8^{\text {th }}$ grade, A class as experimental class and B class as control class.

\section{Result and Discussion}

All results of the research data taken will be analyzed and discussed step by step based on the research questions formed. The report consists of the improvement of students' understanding based on the taxonomy level of bloom, the students' motivation toward the implementation Stellarium as interactive multimedia in learning the solar system as seen in 
Figure 1, and the correlation between the class which using Stellarium and not using Stellarium.

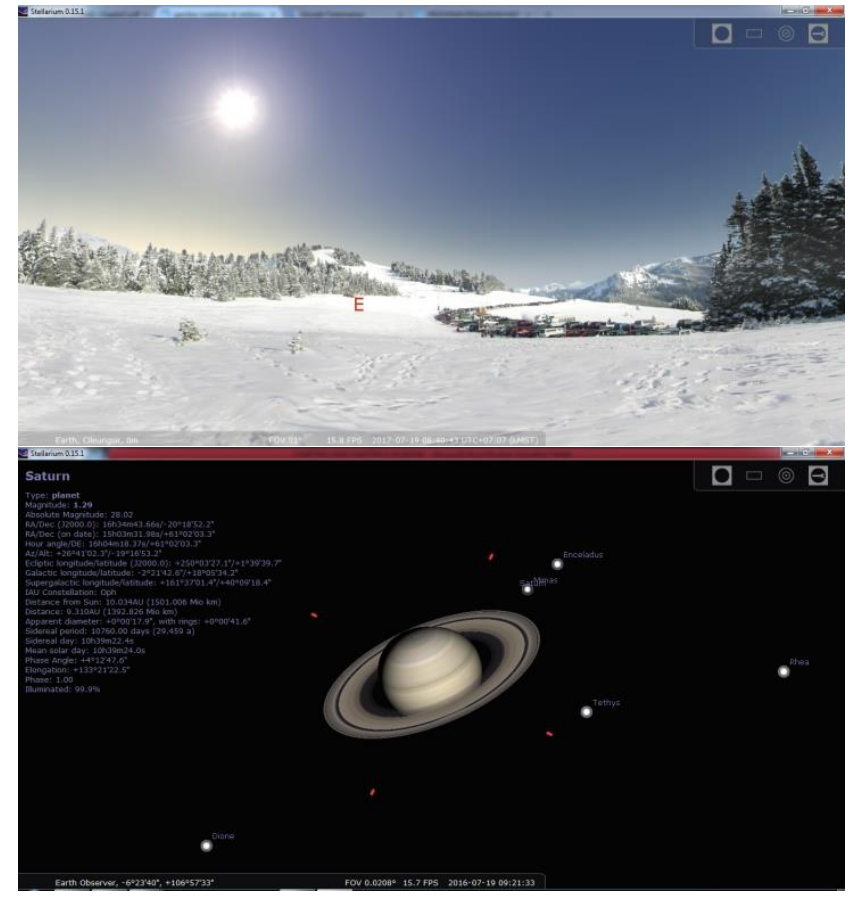

Fig. 1. The Sun view from Earth (above) and the Saturn including satellites (below) from Stellarium

\subsection{Implementation of Stellarium as an Interactive Multimedia for learning Solar system}

The Stellarium has been implemented in one school in Bandung. The implementation of Stellarium was done in the experimental class consists of 20 students. The implementation of Stellarium as interactive multimedia in learning solar systems was done in four meetings. The learning process using Stellarium is tabulated in Table 2.

The observation sheet was signed by the teacher in that school. During the learning process, researchers are supervised by local teachers to help whether learning goes according to the lesson plan. Some obstacles must be overcome by the researcher. The first meeting the learning activates was completed according to the lesson plan. The activities in the first meeting were only about pretest and introduction of Stellarium. For the second meeting has $71 \%$. Because in that meeting the students were excited about Stellarium and they were tried to operate the Stellarium. The third meetings have $91 \%$. Researchers missed one activity in the lesson plan. In the fourth meeting, the students cannot finish the worksheets because of limited time. The last is the fifth meeting has $100 \%$ value. The activity in the last is about the posttest.

The implementation of Stellarium as learning media was conducting in five meetings. In the first meeting, the Stellarium was showed in front of the class using a Projector and the students were paid attention and they were excited because they looked something new for 
them. It can be seen in the video. The activities were run in the class because the researcher doesn't have the opportunity to use the computer lab. Thus, the second meeting until the fourth students were asked to install the Stellarium in their laptop to make time efficiently. In every meeting, they must bring a laptop to learn using Stellarium. The researchers wanted to conduct the research smoothly, but in reality, it sometimes performs not as expected.

Table 2. Implementation of Stellarium

\begin{tabular}{|c|c|}
\hline Days & Activities \\
\hline \multirow[t]{2}{*}{ Day 1} & Conducting Pre-test for objective test and Questionnaire \\
\hline & Introducing Stellarium to students \\
\hline \multirow[t]{4}{*}{ Day 2} & Learning the solar system topic with Stellarium \\
\hline & Distribute the worksheet was about \\
\hline & "Component of Solar System" \\
\hline & Exploration by students in the learning component of the solar system using Stellarium \\
\hline \multirow[t]{3}{*}{ Day 3} & Learning rotation and revolution of the earth topic using Stellarium. \\
\hline & Distribute the worksheet was about "Rotation and Revolution of the earth" \\
\hline & $\begin{array}{l}\text { Exploration by students in learning Rotation and Revolution of the earth using } \\
\text { Stellarium }\end{array}$ \\
\hline \multirow{3}{*}{ Day 4} & Learning Solar and Lunar Eclipse using Stellarium \\
\hline & Distributed the worksheet was about "Solar and Lunar Eclipse" \\
\hline & Exploration of student \\
\hline Day 4 & Distribution posttest and questionnaire \\
\hline
\end{tabular}

\subsection{Students' Understanding Improvement after Learning Solar System using Stellarium}

The data of Student' Understanding was obtained from an objective test consisted of 20 multiple-choice questions. The objective teat was analyzed using Bloom Taxonomy based on level cognitive taxonomy which is $\mathrm{C} 1$ (remembering), C2 (understanding), C3 (applying), C4 (analyzing) and C5 (evaluating). The test item consisted of pre-test and post-test have been tested in term of validity, reliability, discriminating power, and difficulty level then being judged by some experts. The test item was revised so that it is adequate to be used as a research instrument to gain the profile of students' understanding. Thus, the recapitulation of students; understanding based on pre-test and post-test are shown in the following Table 3.

The result shows the means of pretest conducted before the implementation of Stellarium as interactive multimedia in learning solar system is 45.75 and it is improved into 64 as the result of the post-test. The lower score is 30 and the highest is 60 . Meanwhile, the data of the post-test shows that the lowest score is 45 and the highest is 80 . Moreover, it can be seen the difference between the two classes by normalized gain. The normalized gain of the Experimental class is 0.33 and 0.2 for the control class. According to hake, the normalized gain of the experimental class is categorized as medium improvement and low improvement for the control class. It means the class with the implementation of Stellarium is better than learning without Stellarium.

The normality test is to find $\mathrm{N}$-gain data obtained has normal distribution or note in both two groups (experimental group and control group). To measure the distribution of the data, the Shapiro Wilk method is used. If the probability value is greater than $0.05(>0.05)$, then the data is normally distributed, and vice versa. The result of normality using the Shapiro-Wilk method that the value of the experimental group is 0.387 while the control group is 0.168 is 
mean that the value of probability is more than 0.05 . Based on the criteria of normality test from the values of Shapiro-Wilk the data in the experimental and control group had normalized distribution because the value of Shapiro Wilk is 0.397 and $0.168>0.05$. Both of group has normalized distribution the next method is homogeneity if the data was homogeneity the Independent Sample Test is the next step. The homogeneity test aims to determine whether the measured score variance in both samples has the same variance or not. The significant value of the Homogeneity test is 0.05 . The results of the homogeneity test with Levene's test method. Levene value is on the line of Value-Based on Mean, 0.106 with p-value (sig) of 0.746 where $>0.05$ which means there is a similarity of variance between groups or which means homogeneous. Because the data is homogeneous, the next step is the Independent Sample Test.

Table 3. Recapitulation of students' understanding based on pre-test and post-test of experiment and control classes

\begin{tabular}{|c|c|c|c|c|c|c|c|c|c|}
\hline \multirow[t]{2}{*}{ No } & \multirow[t]{2}{*}{ Component } & \multicolumn{4}{|c|}{ Experiment Class } & \multicolumn{4}{|c|}{ Control Class } \\
\hline & & $\begin{array}{l}\text { Pre- } \\
\text { test }\end{array}$ & $\begin{array}{l}\text { Post- } \\
\text { test }\end{array}$ & $\langle\mathrm{g}\rangle$ & Category & $\begin{array}{l}\text { Pre- } \\
\text { test }\end{array}$ & $\begin{array}{l}\text { Post- } \\
\text { test }\end{array}$ & $\langle\mathrm{g}\rangle$ & Category \\
\hline 1 & Participant & 20 & 20 & 0.33 & Medium & 21 & 21 & 0.2 & Low \\
\hline 2 & Average & 45.75 & 64 & & & 41.5 & 52.1 & & \\
\hline 3 & Deviation standard & 9.2 & 10.0 & & & 11.4 & 11.5 & & \\
\hline 4 & Lower Score & 30 & 45 & & & 25 & 35 & & \\
\hline 5 & Higher Score & 60 & 80 & & & 65 & 75 & & \\
\hline
\end{tabular}

An independent sample T-test was used to test the significance of the average difference between the two groups. This test is used to test the effect of the independent variable on the dependent variable. The significance value is 0.05 . The value of sig (2-tailed) is 0.019 which < 0.05 its mean the hypothesis for this research is $\mathrm{H}_{0}=$ rejected, $\mathrm{H}_{0}$ : There is no different of students' understanding in learning solar system using Stellarium as an Interactive Multimedia and no using Stellarium, and $\mathrm{H}_{1=}$ is accepted, $\mathrm{H}_{1}$ : There is different of students' understanding in learning solar system using Stellarium as an Interactive Multimedia and no using Stellarium.

\subsection{Implementation of Stellarium as an Interactive Multimedia for learning Solar system}

The questionnaire was given to the students as a tool to know students respond after the implementation of Stellarium. The questionnaire has been given to the students in the class, the classes are experimental class and control class. Each class is consists of twenty students for experimental class and twenty-one for control class. The questionnaire that has been given to the student consists of 30 statements. It divided into three different topics, there are solar system topic, technology topic, and Stellarium topic. The questionnaire is adapted from International Journal and CODEX.

The researches have calculated the total of a score for each student to respond in a questionnaire. The score of the total average is 100,55 which categorize as Adequately Motivated based on the criteria of Student's motivational Questionnaire. It has the same value with control class the value is 106 categorize as Adequately Motivated. To know which one the statement most agreed by students. Recapitulation of students' understanding based on pre-test and post-test of experiment and control classes can be seen in the table 4 . 
Table 4. Recapitulation of students' understanding based on pre-test and post-test of experiment and control classes

\begin{tabular}{|c|c|c|c|}
\hline \multirow[b]{2}{*}{ No } & \multirow[b]{2}{*}{ Aspects } & \multicolumn{2}{|c|}{ Percentage } \\
\hline & & Experiment & Control \\
\hline \multicolumn{4}{|c|}{ Statement about Learning Solar System } \\
\hline 1 & $\begin{array}{l}\text { I like to study the Solar System because the topic was } \\
\text { interesting and easy }\end{array}$ & $75 \%$ & $77 \%$ \\
\hline 2 & I heard the teacher while explaining the Solar System chapter & $77 \%$ & $72 \%$ \\
\hline 3 & $\begin{array}{l}\text { I didn't pay attention to the teacher when he was explaining } \\
\text { the solar system }\end{array}$ & $72 \%$ & $69 \%$ \\
\hline 4 & $\begin{array}{l}\text { During the lesson, I feel happy when the teacher and friends } \\
\text { appreciated my ideas }\end{array}$ & $72 \%$ & $74 \%$ \\
\hline 5 & $\begin{array}{l}\text { I prefer learning through experiments, playing games, or other } \\
\text { activities. }\end{array}$ & $81 \%$ & $75 \%$ \\
\hline & Average & $75 \%$ & $71 \%$ \\
\hline \multicolumn{4}{|c|}{ Statement about the Use of Technology in Learning } \\
\hline 1 & $\begin{array}{l}\text { I often use technologists like laptops to study because it makes } \\
\text { it easy for me }\end{array}$ & $67 \%$ & $77 \%$ \\
\hline 2 & Technology makes me lazy to take notes & $59 \%$ & $60 \%$ \\
\hline 3 & I like applications that support me in learning. & $71 \%$ & $68 \%$ \\
\hline 4 & I like learning based on visualization & $73 \%$ & $72 \%$ \\
\hline \multirow[t]{2}{*}{5} & $\begin{array}{l}\text { I am sure if all teachers can use technology I will be more } \\
\text { happy in learning }\end{array}$ & $63 \%$ & $73 \%$ \\
\hline & Average & $64,6 \%$ & $67,7 \%$ \\
\hline \multicolumn{4}{|c|}{ Statement about the Implementation of Stellarium } \\
\hline 1 & $\begin{array}{l}\text { After learning to use Stellarium, I can understand the lessons } \\
\text { of the solar system chapter }\end{array}$ & $64 \%$ & $68 \%$ \\
\hline 2 & $\begin{array}{l}\text { I prefer the teacher to explain directly in class rather than } \\
\text { using a Stellarium }\end{array}$ & $64 \%$ & $77 \%$ \\
\hline 3 & I opened the Stellarium at home to learn it & $60 \%$ & $60 \%$ \\
\hline 4 & $\begin{array}{l}\text { I did not pay attention when the teacher taught using a } \\
\text { Stellarium }\end{array}$ & $64 \%$ & $65 \%$ \\
\hline \multirow[t]{2}{*}{5} & $\begin{array}{l}\text { Using the Stellarium makes me dizzy and doesn't understand } \\
\text { the lessons being taught. }\end{array}$ & $64 \%$ & $57 \%$ \\
\hline & Average & $63 \%$ & $65 \%$ \\
\hline
\end{tabular}

According to the table 4 above the average of all aspect in both classes have ranged from $60 \%-79 \%$ which categorized as agree or like. They have not a huge different value of average. Experimental class and control class have the value of average about $75 \%$ and $70 \%$ in first. It means in the experimental class agree that they are like solar system topics. Even though the score is different but it can be seen in each statement both classes have a high score for this aspect. The second aspect has also had the same range, but it can see in the fifth and seventh statements show that in the experimental class were like learning using technology. They are like the application or software which can support learning and visualization based learning. The third aspect is about the implementation of Stellarium both classes still in the same range. They're a fact from the questionnaire, the students in the experimental class were agreeing that they prefer to use Stellarium than learning with teacher explanation. It can be seen in percentage in statement number 3 in the last aspect. They have a $13 \%$ different value 
in statement number 3. Thus, the table is used as a reference that students in the experimental class have enough motivation especially in the last aspect of Stellarium.

\section{Conclusion}

Based on the results of discussion on chapter IV about the implementation of Stellarium as an interactive multimedia on students understanding and students' motivation in learning solar system was placed in one of Independent school in West Bandung at $8^{\text {th }}$ grade can be concluded as (a) The implementation was done well based on the implementation percentage which was reached $90 \%$. (b) There is a significant improvement in students' understanding of learning motivation using Stellarium in learning solar system. The result obtained is from normalized gain from both of class experimental class and control class. The experimental class has the value of average $\mathrm{N}$-gain is about 0.33 and for control, the class is 0.2 . It strengthens with the result of the independent sample test which has the value of sig (2-tailed) is 0.019 which $<0.05$ means the hypothesis for this research is $\mathrm{H}_{0}=$ rejected, $\mathrm{H}_{1=}$ is accepted. (c) The students' motivation in learning solar systems using Stellarium is categorized as adequately motivated which has a value of average motivation is 100.5 . The result that is obtained from interpretation students' motivation which analyzed by the researcher.

\section{References}

[1] Prima, E. C., Utari, S., Chandra, D. T., Hasanah, L., \& Rusdiana, D.: Heat and temperature experiment designs to support students' conception on nature of science. JOTSE: Journal of technology and science education, 8(4), pp. 453-472 (2018)

[2] American Association for the Advancement of Science.: Benchmarks for science literacy. Oxford University Press (1994)

[3] Ornek, F., Robinson, W. R., \& Haugan, M. R.: What Makes Physics Difficult?. Science Education International, 18(3), pp. 165-172 (2007)

[4] Lai, E. R.: Metacognition: A literature review. Always learning: Pearson research report, 24 (2011)

[5] Prima, E. C., Putri, A. R., \& Rustaman, N.: Learning Solar System Using PhET Simulation to Improve Students' Understanding and Motivation. Journal of Science Learning, 1(2), pp. 60-70 (2018)

[6] Leow, F. T., \& Neo, M.: Interactive multimedia learning: Innovating classroom education in a Malaysian university. Turkish Online Journal of Educational Technology-TOJET, 13(2), pp. 99-110 (2014)

[7] Virvou, M., Katsionis, G., \& Manos, K.: Combining software games with education: Evaluation of its educational effectiveness. Journal of Educational Technology \& Society, 8(2), pp. 54-65 (2005). [8] Creswell, J. W.: Educational research: Planning, conducting, and evaluating quantitative (pp. 146166). Upper Saddle River, NJ: Prentice Hall (2002) 